\title{
Novel insights into the animal models of Diabetes Mellitus
}

\author{
Ahmad Farid Habibyar* \\ Department of Pharmacology, Faculty of Pharmacy, Kabul University, Kabul, Afghanistan
}

\begin{abstract}
Animal models of disease have historically played a crucial role in the investigation and explanation of disease pathophysiology and identification of drug targets. Moreover, animal models also played important role in the assessment of new drugs in vivo.

Diabetes mellitus is a group of metabolic ailments, which is characterized by high blood sugar levels for a longer period. To avoid complications of disease and related economic losses and untoward concerns, prevention and early therapy are therefore necessary. Because of the inadequate usefulness of the current therapies, new therapeutic agents are required to be developed. This paper briefly reviews the animal models of type 1 and type 2 diabetes mellitus, which include natural model of diabetes, models of diabetes induced by chemicals, genetic models of diabetes, physiological model, non-obese model, surgery induced model of diabetes mellitus. Our study found that animal models played an important role in the investigation of the pathophysiology of diabetes mellitus. Also, they helped in the understanding of drug targets and testing new drugs for the mentioned disease.
\end{abstract}

\section{Introduction}

Diabetes mellitus is a chronic metabolic illness, it is characterized by a high blood sugar (hyperglycemia), which is caused by relative or absolute lack of insulin. Over passage of time, diabetes results in damage and dysfunction in multiple organ systems (Table 1). Vascular disease is a major cause of many of the sequelae of this disease. Both microvascular disease (retinopathy, nephropathy, neuropathy) that is specific to diabetes and macrovascular disease (coronary artery disease, peripheral vascular disease) that occurs with increased frequency in diabetes contribute to the high morbidity and mortality rates associated with this disease. Neuropathy also causes increased morbidity, particularly by virtue of its role in the pathogenesis of foot ulcers $[1,2]$. Diabetes mellitus has two common types, they are type 1 diabetes and type 2 diabetes. Type 1 diabetes is generally thought to be caused by an immune-associated, destruction of pancreatic $\beta$ cells, which produces insulin $[3,4]$. Therefore, it is thought be an autoimmune disorder, and its most commonly occurring in children and younger adults [5]. The control of the illness through monitoring the blood glucose, and insulin administration from outside is hard and expensive, which result in

Table 1. Chronic complications of diabetes mellitus.

\begin{tabular}{|l|}
\hline Microvascular disease \\
\hline Nephropathy \\
\hline Neuropathy \\
\hline Sensorimotor distal symmetric neuropathy \\
\hline Autonomic neuropathy \\
\hline Focal and multifocal neuropathies \\
\hline Vascular \\
\hline Nonvascular (entrapment) \\
\hline Macrovascular disease \\
\hline Coronary artery disease \\
\hline Cerebrovascular disease \\
\hline Peripheral vascular disease \\
\hline Associated complications \\
\hline Foot ulcers \\
\hline Infections \\
\hline
\end{tabular}

higher or lesser level of blood glucose levels, which is associated with additional systemic disorders [6,7]. The problem in type 2 diabetes (T2D) is the insulin resistance and there is no adequate compensation by the beta cells, together insulin resistance and no compensation leads to a relative insulin deficiency [8]. Therefore, both kinds of endocrine disorders represent quite complex states with the involvement of different bodily systems. Therefore, it is required to carefully choose the animal models for diabetes research. Moreover, animal models play a pivotal role in the exploration of the pathophysiology of diabetes mellitus [9]. Insulin deficiency of type 1 diabetes can be attained in a variety of ways, these ranges from chemical damage to the beta cells to breeding animals (rodents) which develop autoimmune disease (diabetes) spontaneously. A number of animal models for understanding the pathophysiology and the resulting complications of type 2 diabetes mellitus have been developed [10].

Additionally, a number of animal models for type 2 diabetes mellitus have been developed which also has obesity. This reflects the linkage between obesity and diabetes, a condition similar to that of the human type i.e. connection between obesity and diabetes mellitus. These animal models have abnormality in one or more genes that are connected to obesity and insulin resistance, which leads to the development of hyperglycemia [11].

There are a number of factors that affect pathogenesis of diabetes mellitus and its complications; they include obesity, insulin resistance, hyperglycemia, hyperlipidemia [9]. The aim of this study is to review the animal models that are used in the experiments and research of diabetes mellitus (Figure 1).

Correspondence to: Ahmad Farid Habibyar, Department of Pharmacology, Faculty of Pharmacy, Kabul University, Kabul, Afghanistan, E-mail: drfaridhabibyar@gmail.com

Key words: Diabetes mellitus, hyperglycemia, neuropathy

Received: November 15, 2016; Accepted: December 08, 2016; Published: December 12, 2016 


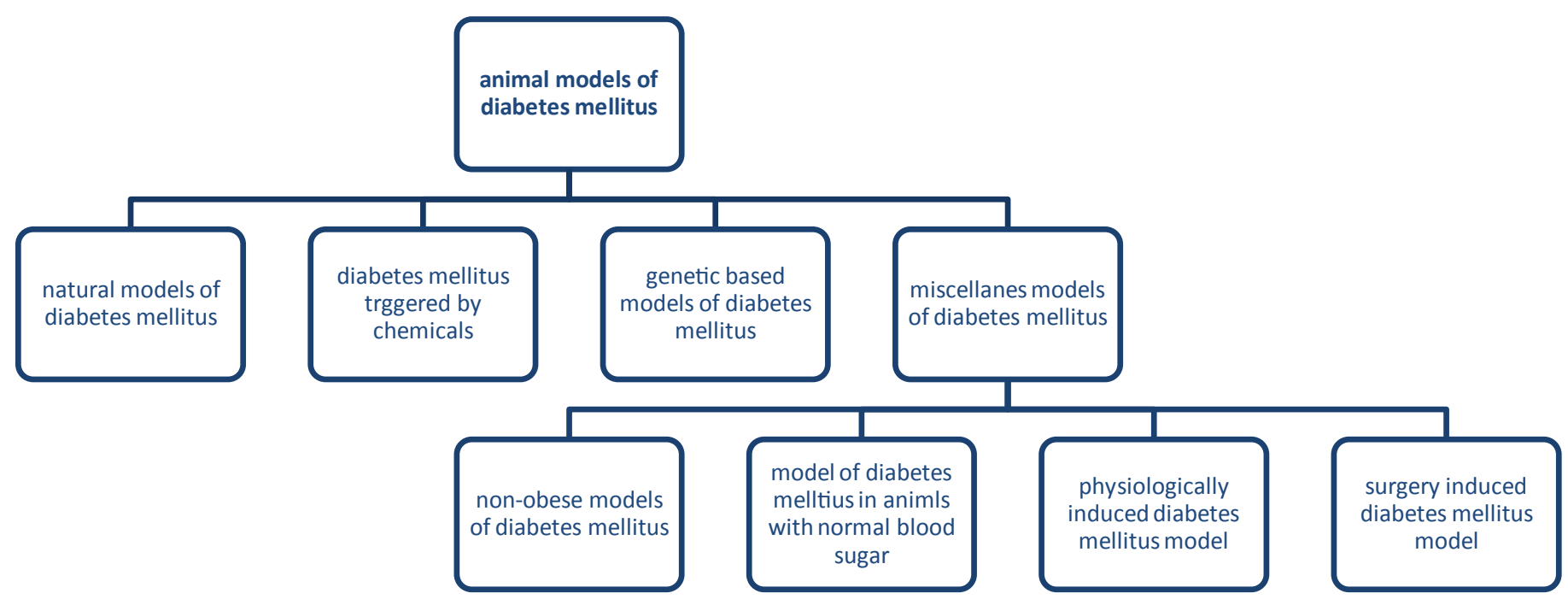

Figure 1. Animal models of diabetes mellitus.

The animal models used in the pharmacological experiments are classified as follows:

\section{Natural models of diabetes mellitus}

These models are based on the reality that they develop diabetes mellitus without using alloxan or streptozotocin and thus allowing for investigating the actions of antidiabetic phytoconstituents [12]. There are a number of genetic animal models of diabetes for instance GotoKakizaki, which is model for type 2 diabetes mellitus. This model is developing spontaneously by selective breeding over many generations [13]. For producing animal model of type 1 diabetes mellitus, animals develop diabetes between 12 and 30 weeks of age, while in some models like BB rats, it take 3 months to develop diabetes mellitus type 1 . An important property of these models is that they can be used to study complications of diabetes mellitus like atherosclerosis and test the effect of drugs [14,15].

\section{Diabetes mellitus models triggered by chemicals}

There are some chemicals, which can be used to induce diabetes. These chemicals are streptozotoicn and alloxan. These two diabetogenic chemicals accumulate in the beta cells of the pancrease. The help of glucose transporter 2 mediates this action. The methyl nitrsourea moiety of the streptozocin is responsible for its cytotoxic activity on the pancreatic beta cells. This moiety alkylates DNA of the mentioned cells, resulting in the fragmentation of DNA [15]. Some studies report that diabetes mellitus induced by strepotozocin can improve the cardiac recovery from ischemia repserfusion [16]. Additionally, it decreases the occurrence of cardiac arrhythmia [17,18]. On the contrary, there are some published studies, which are reporting that diabetes induced by streptozotocin, couldn't decrease the infarct size, even it can't prevent the occurrence of arrhythmia [19-23]. Also it leads to the enlargement of the infarct size. Alloxan is another diabetogenic chemical, it leads to the pathogensis of diabetes mellitus through two different actions. It inhibits the enzyme glucokinase, thus it inhibits glucose induced insulin secretion. Moreover, alloxan induces diabetes through the production of reactive oxygen speices and subsequent beta cells' necrosis [15].

\section{Genetic based models of diabetes}

\section{Zucker diabetic fatty rats}

These rats are discovered in the year 1961. They have mutated leptin receptor, which leads to the hyperphagia, as a result the rats become obese by fourth weeks of age [24]. These rats also have hyperinsulinemia, hyperlipidemia, hypertension, as well as compromised glucose tolerance. The development of type 2 diabetes in male rats (after feeding with high-energy diet) is attributed to the homozygous mutation that occurs in the leptin receptor [25]. After 3 weeks up to two months of age, the animals develop insulin resistance as well as glucose intolerance. Between 2 and 2.5 months of age they will be clearly developing diabetes. In this model the hyperplasia of the Islet of langarhans is contributing to the development of high blood insulin levels [26].

In obese rats, the level of cholesterol and trigeglycerides is higher than slim rats. These high levels of lipids and increased lipid metabolism causes lipotoxicity in the skeletal muscle as well as in the panceatic islet cells [27-29]. These products resulted from the lipid metabolism is attributed to the obesity complications, resistance to insulin, cardiovascular problems and diabetes. These metabolic products disrupts the cell funtions, eventually they cause programmed cell death i.e. apoptosis [26,29].

\section{Transgenic and knock out models of diabetes mellitus}

These animal models are produced either through transfer of gene from diabetic animal to normal animal (transgenic), or they are generated by removing the normal gene (knock out) required for making enzymes needed for glucose metabolism [30]. These animal models can be produced only in those labs where the sophisticated equipment and techniques are available.

\section{Miscellaneous models of diabetes mellitus}

\section{Non-obese diabetic mouse model}

This model was developed in 1974 in Osaka, Japan at Shinogi laboratories. In this model the animals develop insulitis at the age of third or fourth weeks. This period is called prediabetic time, the change occurs in this stage is the CD4+ and CD8+ lymphocytes infiltration into 
the islet cells [31]. Additionally natural killer cells and B-lymphocytes also exist their [32].

While infiltrated the immune cells into the islets of langarhans, at the age of $4-6^{\text {th }}$ weeks, they attract CD4+ and CD8+ subsets, which are essential for development of diabetes. The incidence of insulitis causes the beta cells to destroy. Diabetes usually appears after $90 \%$ of the pancrease insulin is lost at the age of 10-14 weeks, diabetes can develop even up to the 30 weeks of life [33].

After the appearance of diabetes, mice loses weight rapidly, thus they require treatment with insulin. The non-obese diabetic mice model is used to study type 1 diabetes mellitus. Moreover, in this model the animals develop spontaneous disease similar to human beings. This model served in the pathological understanding of diabetes, including the knowledge about auto antigens and biomarkers similar to human beings, which helped in developing antidiabetic medicines [34].

In the nonobese mice as well as in the human beings the genetic factor that renders susceptibility to type 1 diabetes mellitus is MHC (major histocompatibility complex), [35,36]. More than forty genetic loci are present which render non-obese mice as well as the humans susceptible to type 1 diabetes, including genes relevant to immune system and pancreatic beta cells function [37].

Dendritic cells, macrophages and neutrophils infiltrate the pancrease of the non-obese diabetic animals at the age of three weeks [38-40].

Several studies reported that MHC class-II proteins in non-obese mice and in the human beings are similar structurally, this confer both of them to be susceptible or resistant to disease [41].

This genetic similarity between human beings and non-obese diabetic mice has been used to understand the mechanisms of type 1 diabetes mellitus [42].

It is mentionable, that there are some drugs, which were proved effective in mice in this model, but failed to be effective in human beings [43]. The limitations of this model include the time point of interventions, translating the therapeutics tested in non-obese diabetic mice, dosing translation from mice to animals [44]. Another limitation is that the mice should be kept away from microbial pathogens, otherwise this can result in negative association of the animals with diabetes mellitus [45].

\section{Model of diabetes mellitus in animals with normal blood sugar}

In this model, the normal animals can be used to test the effect of anti-diabetic drugs. In addition to other models, this is still used for pharmacological screening of the antidiabetic drugs. This model allows studying the action of drugs with antidiabetic effect in animals with intact pancreas [46]. Additionally, this model is also useful to understand the action of diabetogenic drugs.

\section{Physiologically induced diabetes mellitus model}

In this model the blood sugar level of the animal is increased without any damage to the insulin producing gland i.e. pancrease. This method is also known as the tolerance testing of glucose. In this model the animals are fasted overnight. After one day the animals are given glucose (p.o. 1-2.5 g/kg), the blood sugar is monitored periodically. In this model the animals which can be used include the rabbits and/ or male rats [47].

\section{Surgery induced diabetes mellitus model}

In this model the pancreas gland is removed through the surgery. The animal species, on which this model is applied, include rats, dogs, monkeys and pigs. There are few number of researches employed this animal model to evaluate the actions of phytoconstituents $[46,47,48]$.

Demerits of this model include, technical and sanitary environmental requirement for surgery, as well as the risk of animal infection, post-operative care etc. For achieving mild to moderate high blood sugar levels, it is required to remove $>80 \%$ of pancrease gland. In this regard, if a small portion of the remaining gland is removed it can lead to significant reduction in the blood levels of insulin $[46,48]$.

\section{Conclusion}

Diabetes mellitus is a global burden. It can leads to economic and humanistic disasters worldwide. A number of animal models of diabetes are developed at the preclinical level. These models helped to explore the actions of phytoconstituents on the animal species. Additionally, animal models contributed a lot in the exploration of the pathophysiology of diabetes mellitus and its complications. Similarly, these animal models also played an important role in discovering new therapeutic agents for both types of diabetes mellitus. Despite these all achievements made in the field of diabetes mellitus, there are still some shortages and limitations with the existing models. Thus, it is required for the relevant scientists and researchers to discover more models of diabetes that can be useful in understanding the mechanisms of disease and exploration of new therapeutic agents accordingly.

\section{References}

1. Danaei G, Finucane MM, Y Yuan L, Gitanjali S, Cowan M, et al. (2011) National, regional, and global trends in fasting plasma glucose and diabetes prevalence since 1980: systematic analysis of health examination surveys and epidemiological studies with 370 country-years and 2.7 million participants. The Lancet $378: 31-40$.

2. McPhee SJ, Hammer GD (2010) Pathophysiology of disease: an introduction to clinical medicine. ( $6^{\text {th }}$ edition) McGraw-Hill: 22.

3. Bluestone JA, Herold K, Eisenbarth G (2010) Genetics, pathogenesis and clinical interventions in type 1 diabetes. Nature 464: 1293-1300. [Crossref]

4. Todd JA (2010) Etiology of type 1 diabetes. Immunity 32: 457-467. [Crossref]

5. Hyttinen V, Kaprio J, Kinnunen L, Koskenvuo M, Tuomilehto J (2003) Genetic liability of type 1 diabetes and the onset age among 22, 650 young Finnish twin pairs: a nationwide follow-up study. Diabetes 52: 1052-1055. [Crossref]

6. Tao B, Pietropaolo M, Atkinson M, Schatz D, Taylor D (2010) Estimating the cost of type 1 diabetes in the U.S.: a propensity score matching method. PLoS One 5: e11501. [Crossref]

7. Ben Nasr M, D'Addio F, Usuelli V, Tezza S, Abdi R, et al. (2015) The rise, fall, and resurgence of immunotherapy in type 1 diabetes. Pharmacol Res 98: 31-38. [Crossref]

8. Solomon TPJ, Sistrun SN, Krishnan RK Del Aguila LF, Marchetti CM, et al. (2008) Exercise and diet enhance fat oxidation and reduce insulin resistance in older obese adults. Journal of Applied Physiology 104: 1313-1319.

9. Arndt T, Jörns A, Weiss H, Tiedge M, Hedrich HJ, et al. (2013) A variable CD3+ T-cell frequency in peripheral blood lymphocytes associated with type 1 diabetes mellitus development in the LEW.1AR1-iddm rat. PLOS ONE 8: e64305.

10. Calcutt NA, Cooper ME, Kern TS, Schmidt AM (2009) Therapies for hyperglycaemiainduced diabetic complications: from animal models to clinical trials. Nature Reviews Drug Discovery 8: 417-429. [Crossref]

11. Kawano K, Mori S, Hirashima T, Man ZW, Natori T (1999) Examination of the pathogenesis of diabetic nephropathy in OLETF rats. $J$ Vet Med Sci 61: 1219-1228. [Crossref]

12. Masiello P (2006) Animal models of type11 diabetes with reduced pancreatic?-cell mass. The International Journal of Biochemistry and Cell Biology 38: 873-893. [Crossref] 
13. Chen D, Wang MW (2005) Development and application of rodent models for type 2 diabetes. Diabetes Obes Metab 7: 307-317. [Crossref]

14. Wu KK, Huan Y (2007) Diabetic atherosclerosis mouse models. Atherosclerosis 191: 241-249. [Crossref]

15. Lenzen S (2008) The mechanisms of alloxan- and streptozotocin-induced diabetes. Diabetologia 51: 216-226. [Crossref]

16. Moon CH, Jung YS, Lee SH, Baik EJ (1999) Protein kinase C inhibitors abolish the increased resistance of diabetic rat heart to ischemia-reperfusion injury. Japanese Journal of Physiology 49: 409-415.

17. Chen H, Shen WL, Wang XH, Chen HZ, Gu JZ, et al. (2006) Paradoxically enhanced heart tolerance to ischaemia in type 1 diabetes and role of increased osmolarity. Clinical and Experimental Pharmacology and Physiology 33: 910-916.

18. Ravingerova T, Matejikova J, Pancza D, Kolar F (2009) Reduced susceptibility to ischemia-induced arrhythmias in the preconditioned rat heart is independent of PI3 Kinase/Akt. Physiological Research 58: 443-447.

19. Kim HS, Cho JE, Hwang KC, Shim YH, Lee JH, et al. (2010) Diabetes mellitus mitigates cardioprotective effects of remifentanil preconditioning in ischemiareperfused rat heart in association with anti-apoptotic pathways of survival. European Journal of Pharmacology 628: 132-139.

20. Yadav HN, Singh M, Sharma PL (2010) Involvement of GSK-3 $\hat{\mathrm{I}}^{2}$ in attenuation of the cardioprotective effect of ischemic preconditioning in diabetic rat heart. $\mathrm{Mol} \mathrm{Cell}$ Biochem 343: 75-81. [Crossref]

21. Ajmani P, Yadav HN, Singh M, and Sharma PL (2011) Possible involvement of caveolin in attenuation of cardioprotective effect of ischemic preconditioning in diabetic rat heart. BMC Cardiovascular Disorders 11: article 43.

22. Ji L, Zhang X, Liu W Huang Q, Yang W, et al. (2013) AMPK-regulated and Aktdependent enhancement of glucose uptake is essential in ischemic preconditioningalleviated reperfusion injury. PLOS ONE 8: e69910.

23. Vinokur V, Berenshtein E, Bulvik B, Grinberg B, Eliashar R, et al. (2013) The bitter fate of the sweet heart: impairment of iron homeostasis in diabetic heart leads to failure in myocardial protection by preconditioning PLOS ONE 8: e62948.

24. Phillips MS, Liu Q, Hammond HA, Dugan V, Hey PJ, et al. (1996) Leptin receptor missense mutation in the fatty Zucker rat. Nat Genet 13: 18-19. [Crossref]

25. Srinivasan K, Ramarao P (2007) Animal models in type 2 diabetes research: an overview. Indian J Med Res 125: 451-472. [Crossref]

26. Tokuyama Y, Sturis J, DePaoli AM, Takeda J, Stoffel M, et al. (1995) Evolution of beta-cell dysfunction in the male Zucker diabetic fatty rat. Diabetes 44: 1447-1457. [Crossref]

27. Lee Y, Hirose H, Zhou YT, Esser V, McGarry JD, et al. (1997) Increased lipogenic capacity of the islets of obese rats: a role in the pathogenesis of NIDDM. Diabetes 46 : 408-413. [Crossref]

28. Shimabukuro M, Higa M, Zhou YT, Wang MY, Newgard CB, et al. (1998) Lipoapoptosis in beta-cells of obese prediabetic fa/fa rats. Role of serine palmitoyltransferase overexpression. The Journal of Biological Chemistry 273: 32487-32490.

29. Shimabukuro M, Zhou YT, Levi M, and R. H. Unger RH (1998) Fatty acid-induced $\beta$ Cell apoptosis: a link between obesity and diabetes. Proceedings of the National Academy of Sciences of the United States of America 95: 2498-2502. [Crossref]

30. Hanafusa T, Miyagawa J, Nakajima H, Tomita K, Kuwajima M, et al. (1994) The NOD mouse. Diabetes Res Clin Pract 24 Suppl: S307-311. [Crossref]
31. Yoon JW, Jun HS (2004) Viruses in type 1 diabetes: brief review. ILAR J 45: 343-348 [Crossref]

32. Miyazaki A, Hanafusa T, Yamada K Miyagawa J, Fujino-Kurihara H, et al. (1985) Predominance of $\mathrm{T}$ lymphocytes in pancreatic islets and spleen of pre-diabetic nonobese diabetic (NOD) mice: a longitudinal study. Clinical and Experimental Immunology 60: 622-630. [Crossref]

33. Pearson JA, Wong FS, Wen L (2016) The importance of the Non Obese Diabetic (NOD) mouse model in autoimmune diabetes. J Autoimmun 66: 76-88. [Crossref]

34. Singal DP, Blajchman MA(1973) Histocompatibility (HL-A) antigens, lymphocytotoxic antibodies and tissue antibodies in patients with diabetes mellitus. Diabetes 22: 429432. [Crossref]

35. Nerup J, Platz P, Andersen OO, Christy M, Lyngsoe J, et al. (1974) HL-A antigens and diabetes mellitus. Lancet 2: 864-866. [Crossref]

36. Noble JA, Erlich HA (2012) Genetics of type 1 diabetes. Cold Spring Harb Perspect Med 2: a007732. [Crossref]

37. Jansen A, Homo-Delarche F, Hooijkaas H, Leenen PJ, Dardenne M, et al. (1994) Immunohistochemical characterization of monocytes-macrophages and dendritic cells involved in the initiation of the insulitis and $\beta$-cell destruction in NOD mice. Diabetes 43: 667-675. [Crossref]

38. Bouma G, Coppens JMC, Mourits S Nikolic T, Sozzani S, et al. (2005) Evidence for an enhanced adhesion of DC to fibronectin and a role of CCL19 and CCL21 in the accumulation of DC around the pre-diabetic islets in NOD mice. European Journal of Immunology 35: 2386-2396.

39. Diana J, Simoni Y, Furio L, Beaudoin L, Agerberth B, et al. (2013) Crosstalk between neutrophils, B-1a cells and plasmacytoid dendritic cells initiates autoimmune diabetes. Nature Medicine 19: 65-73. [Crossref]

40. Todd JA, Wicker LS (2001) Genetic protection from the inflammatory disease type 1 diabetes in humans and animal models. Immunity 15: 387-395. [Crossref]

41. Yang Y, Santamaria P (2006) Lessons on autoimmune diabetes from animal models. Clin Sci (Lond) 110: 627-639. [Crossref]

42. Von Herrath M, Filippi C, Coppieters K (2011) How viral infections enhance or prevent type 1 diabetes-from mouse to man. J Med Virol 83: 1672. [Crossref]

43. Von Herrath M, Nepom GT (2009) Animal models of human type 1 diabetes. Nat Immunol 10: 129-132. [Crossref]

44. Christianson SW, Shultz LD, Leiter EH (1993) Adoptive transfer of diabetes into immunodeficient NOD-scid/scid mice. Relative contributions of CD4+ and CD8+ T-cells from diabetic versus prediabetic NOD.NON-Thy-1a donors. Diabetes 42: 4455. [Crossref]

45. Williamson EM, Okpoko DT, Evans FJ (1996) Pharmacological methods in phytotherapy research. New York: John Wiley and sons, Inc.

46. Etuk EU (2010) Animals models for studying diabetes mellitus. Agric Biol J N Am 1: 130-134.

47. Choi SB, Park CH, Choi MK, Jun DW, Park S (2004) Improvement of insulin resistance and insulin secretion by water extracts of Cordiceps militaris, phellinus linteus and paecilomyce tenuipes in 90\% pancreatectomized rats. J Biotech and Biochem 68: 2257-2264.

48. Rees DA, Alcolado JC (2005) Animal models of diabetes mellitus. Diabet Med 22 359-370. [Crossref]

Copyright: (C2016 Habibyar AF. This is an open-access article distributed under the terms of the Creative Commons Attribution License, which permits unrestricted use, distribution, and reproduction in any medium, provided the original author and source are credited. 